\title{
Charting Diversity and Change in IS Publications: A Tri-Continental Journal Analysis
}

\author{
Susan Keller \\ Deakin University \\ susank@deakin.edu.au \\ Darryl Coulthard \\ Deakin University \\ darryl.coulthard@deakin.edu.au
}

\begin{abstract}
The past decade has seen enormous changes in the availability, use, and application of information systems. Information systems are no longer the preserve of business and the corporation but have become a routine part of everyday life. The purpose of this paper is to explore the extent to which the increased diversity in the application and use of information systems in the past decade has been reflected in increased diversity of the publications of three key journals of three continents - North America, Europe, and Australasia. The paper contributes to the debate on research diversity in Information Systems in three ways. Firstly, it describes four key underpinning dimensions for understanding Information Systems (IS) research diversity in the information age. Secondly, it details the results of a content analysis which examines the trends in research and methodological diversity within the journals MIS Quarterly (MISQ), European Journal of Information Systems (EJIS) and the Australasian Journal of Information Systems (AJIS) during the years 2001-2010. Finally, the paper reflects on diversity within these journals and discusses the findings in the context of both exogenous and endogenous pressures on the discipline more broadly.
\end{abstract}

Keywords: research pluralism, journal content analysis, research methods, discipline reflection.

\section{INTRODUCTION}

It is almost trite to observe that over the past decade or so we have seen major changes to information systems and their use. Quite possibly, the most clear and most novel change over this period has been the rise in ubiquitous information systems (UIS) and the rise of the digital native (Vodanovich et al. 2010). UIS refers to the rise of eEverything and the penetration of information systems not only in our working lives and business operations but into our lives and the way in which we shop, socialise, entertain, learn, coordinate meetings, seek information and find news.

Within the Western world, people are becoming 'digital natives' (Vodanovich et al. 2010). This does not mean that everyone is adept at Web2.0, Excel, Jabber or tweeting and texting but that we all come across and interact with some forms of electronic information systems on a daily basis and that most people have, at the very least, become resigned to the fact that they do have to learn the rudiments to 
participate to some extent in the world. As Hillis (2011) among others has suggested we are now irretrievably entangled in the Internet and information systems whether we realise it or not.

Reliable technology uptake statistics are difficult to obtain but the growth in internet based information systems appears is extraordinary. One estimate suggests that Internet users world-wide have increased by around $480 \%$ in the period 2000 and 2011(InternetWorldStats 2011). Other studies suggest that during the decade to 2010, the percentage of adults in the US who access the internet via broadband has grown from $3 \%$ to $66 \%$ (Smith 2010), and in the four years to 2011, mobile-broadband subscriptions globally have increased $45 \%$ annually (ITUTelecom 2011). Incredibly, there are now twice as many mobile broadband subscriptions as fixed broadband (ITUTelecom 2011). By any account, social media use has exploded in the past five years. A study of US adult Internet users in 2011 found that sixty-five per cent now say they use a social networking site like Facebook or LinkedIn. Coupled with mobile broadband, social media is increasingly being consumed and produced via smart phones. In 2011, a Nielson poll showed that close to $40 \%$ of social media users in the US accessed content from a mobile phone (Nielson 2011), and the market research company comScore, reported a $44 \%$ increase in the number of people accessing social networking via a mobile in France, Germany, Italy, Spain and the U.K during 2011 (Comscore 2011).

There are also now hundreds of thousands of mobile and other applications that are changing the way people interact with business and government, and that are blurring the boundaries between work life and social life. This can be seen in the growing trend of virtual work where professionals work remotely from home, client locations, or on the road (Busch 2011; Mulki et al. 2009). Already some Fortune 500 companies including Accenture, AT \& T and IBM have totally or partially eliminated traditional offices, and the increasing globalisation of work is expected to accelerate this trend in the coming decades (Mulki et al. 2009).

By contrast, information systems within businesses have arguably matured rather than changed dramatically. More efficient systems, better alignment to strategic goals and the tantalising prospects of data mining beckon but one would be hard pressed to suggest that the real story of the first decade of the 21 st century was a revolution in business processes in comparison with this penetration of the Internet and ICT generally into everyday life. Most of the largest growing companies Google, Apple, Samsung, Facebook etc. have grown in tandem with, and as a result of, the rise of the digital native and the penetration of information systems into everyday life. The challenge for business is less operational efficiency but how to exploit the rise of ubiquitous systems, big data, social media and the digital natives for competitive advantage.

Business and corporations may then no longer be the sole or even main catalyst for change in information systems and their impact on the world. The rise of the digital native and the extensive use of information systems outside of business and the corporation has meant that information systems have become a routine part of everyday life, often changing how we live and work (Brockman 2011; Yoo 2010). As Simmons (2011 p.589) suggests:

I cannot think of anything that has the potential to change social and political relationships as much as the production, dissemination, and use of new information technologies and new ways to communicate globally.

The locus of change in information systems as a phenomenon appears to be moving from primarily the business sphere to the social sphere. This massive change prompts the questions of how indeed 
does UIS change the way we live, think, work and do business? The fundamental changes in technology use in the past decade challenge the discipline with an expanded research agenda and we suggest that the rise of UIS over the past decade frames a raft of new research questions for the discipline.

On prima facie grounds, one could quite easily suggest that the discipline of Information Systems should be at the forefront of these changes. However, it is a moot point, as to whether Information Systems has kept up with, let alone foreshadowed or led these changes from business and laboratory to 'eSociety' or indeed 'eEverything'. Our initial and provisional forays into the IS literature did not identify a strong sense of following, let alone leading, the development of ICT in the everyday and it was only at the very end of the decade that papers such as Yoo (2010), identifying these developments, were being published in the most highly esteemed journals. This led us to consider the diversity of our most highly prized journals and also their ability to reflect and lead intellectual development of the discipline.

For this paper, our question was whether this profound change in emphasis from business to social use of information systems has been reflected in changes to the academic IS literature. Has the focus of IS research study changed to reflect these broader changes, or does it remain essentially concerned with the application of technology in the business setting? Is IS essentially about the development of more effective and efficient information systems for business applications or has it followed the computer out into the social world? Whether or not we have overstated the penetration of IS into the everyday, we would expect, that the academic journals would at the very least reflect something of this development.

While the concept of an academic discipline is not a straightforward one, a discipline is defined at least in part by the academic journals in which research is published. Thus, to explore these dimensions of diversity in Information Systems we decided to focus on what was being published rather than what was being argued for or against. As Siderova et al. (2008:469) have observed "the body of published IS research can be considered to be the stakeholders' reflection on the IS field identity" (emphasis in original). This is further supported by Benbasat and Zmud (2003), who see what IS researches and thus publishes as signalling its intellectual core.

To this end, we selected three English language journals of general Information Systems across three continents that are key journals and highly influential in each respective continent: MIS Quarterly (MISQ) in North America, the European Journal of Information Systems (EJIS) in Europe, and the Australasian Journal of Information Systems (AJIS) in Australasia. Each is amongst the top ranked generalist journals of their continent in the AIS Journal rankings list (AIS Journal rankings). The choice of continents was to reflect the nature of Information Systems as being at least to some degree context specific - research topics in one country may not be considered as important or as generalizable to other countries. AJIS is, by various measures, rated as being lower than either MIS or EJIS in international rankings. The effect of this difference we believe is however muted by the influence of the journals themselves within their respective continents and the vagaries and politics of the determination of rankings.

A ten year period 2001-2010 was chosen to identify changes to IS following the widespread adoption of high-speed Internet and the emergence of social networking and mobile computing. 
Previous studies have suggested that there exists differences between North American and European journals (Galliers et al. 2007; Gallivan et al. 2007). Specifically, North American journals are seen as more methodologically conservative, leaning heavily to positivist paradigms and favouring quantitative and survey methods. European journals on the other hand have been found to be more likely to favour new approaches most notably interpretive approaches, case studies and qualitative work (Mingers 2003;Benbasat \& Weber, 1996).

To date, no Australian journal content analyses have been conducted although the nature of IS research in Australia has been discussed in the literature (see for example Gregor et al. 2007).

Our attention and focus of this paper is twofold: mapping diversity, and mapping the changing nature of research in the selected journals. Diversity concerns itself with pluralism and providing the opportunity for the expression of a range of viewpoints and types of research to be published. To use a simile, diversity in research journals is like genetic mutation in evolution, it forms the spark for disciplinary growth and 'evolution': one might expect that more diverse journals are by their very nature more responsive to emerging trends.

Diversity can refer to two central elements: diversity of the source of research - the characteristics of those who are published and diversity of outcome - what is published. Diversity of the source of research can be readily identified by the characteristics of the authors but diversity of outcome - the things being published - is a far more difficult to operationalize. What is published then becomes not only a measure of diversity but also of change.

Our research purpose is to explore whether (1) there is diversity of the sources and outcome of research (2) to chart the change in the types of research published in three key journals since 2001 and (3) to consider the findings in the light of the rise of ubiquitous information systems.

To accomplish these aims, the paper is organised as follows. We first discuss the operationalization of diversity and measurement of change, and develop a set of research questions. We do this by reviewing previous studies aimed at understanding diversity in IS research. In particular, we review the classification schemes previously used to capture dimensions of diversity in IS publications and explain why they may be inadequate for tracking changes in the new world of the digital native and ubiquitous computing. Next, we explain our research approach and method, and present the results of the content analysis of the three journals (MISQ, EJIS and AJIS) over the ten year period from 2001 to 2010. We conclude with a reflection on diversity within the three journals and consider the findings in relation to both exogenous and endogenous pressures on the discipline.

\section{THE DIMENSIONS OF THE IS FIELD}

Over the past twenty-odd years, many publication content and citation analyses have been undertaken with a variety of aims, including determining diversity and change within the discipline.

Evaluating diversity in publications depends on determining what the key characteristics of diversity are. Benbasat and Weber (1996) characterised diversity in IS research as: diversity in the problems addressed; diversity in the theoretical foundations and reference disciplines used to account for IS phenomena; and diversity in the methods used to collect, analyse, and interpret data. Benbasat and Weber are primarily concerned with diversity of publication outcome -that is, what is published. 
However in addition to this, a second dimension on diversity is the source of publications, such as the gender and country of the author or even originating discipline.

\section{Previous Diversity Studies}

To develop our diversity criteria we analysed the past Information System journal publication content analyses of other diversity studies (see Appendix A for list and rationale for inclusion). From this it became apparent that most researchers have classified research in the same way as Benbasat and Weber (1996). That is, the 'what' and 'how' of published outcomes. Some work has also looked in a limited way at the source of research, that is, who publishes and who makes publishing decisions (see Appendix A).

Encapsulating the 'what' that has been published provides a particular problem of granularity. On the one hand categories can be drawn so broadly that fluctuations and change in the publication record cannot be realistically observed, whereas fine distinctions between concepts and problems tackled leads to a false impression of diversity of published outcome. Fortunately, as a result of the 'methodology wars' of the 1990s (Orlikowski et al. 1991; Weber 2004) methodological differences or 'research paradigms' have been well established and more or less agreed upon levels of granularity and distinction are easily identified. A key challenge was to develop a framework of similar robustness for research areas or subject matter. On the other hand, diversity measures relating to the source of research appeared more straightforward. These measures could include who was undertaking the research as identified by gender, region and faculty.

\section{Diversity in Subject Matter of Investigation}

Our first major task was to operationalise 'what' is published in IS such that the measure was sufficiently sensitive to identify whether IS remains primarily focussed on business imperatives or there is a shift to exploring the increasingly social drivers and use of information systems while not being swamped by other changes.

Although researchers have used various measures of 'subject matter' diversity including the theories and reference disciplines used in IS, the table in Appendix A shows that researchers have most frequently examined the subject matter of research by analysing topics and themes. These studies have applied a variety of classification schemes, some fine-grained and some at higher levels of abstraction. The scheme devised by Barki, Rivard, and Talbot (1993) has informed many of the studies. In this work, Barki et al. (1993) analysed the keywords of approximately 2,000 papers in six journals during 1987 to 1992 to arrive at a very detailed classification scheme for IS research under the following nine high-level categories: reference disciplines; external environment; information technology; organisational environment; IS management; IS development; IS usage; Information Systems; and IS Education and research. Other IS classification schemes have been developed since this time (see for example Larsen et al. 2008; Sidorova et al. 2008) and also Lamp, J (2011 pp30-40) for discussion of the different attempts to categorise and classify the IS domain. However, all these schemes are fundamentally alike in that they classify the topics and subjects of interest in IS using an inductive approach. Our approach was to use a content analysis but on the dimensions of interest to the study.

The problem is that how we identify and define a phenomenon limits what we will discover about that phenomenon (Sansone et al. 2004:6). While previous topic analyses have provided a surface picture 
of topics, they have not revealed the deeper values or beliefs that "circumscribe definitions of "worthwhile problems"' (Chua 1986:602). So while schemes that categorise what we research by topic are useful for tracking themes and the emergence of new areas they do not develop our understanding of the IS research domain significantly past "IT and ..." as more and more situations are added where IT plays a role. What is needed is a view of the research domain that is at a higher semantic level than previous topic category schemas. What is required is a categorisation of topic similar in granularity and distinction as that of research methodology.

To this end, we have developed the concept of research domain with initially three basic dimensions. Our key interest was to investigate whether there was any change from a business to a social focus and these two dimensions were developed to identify research with either as primary aims. For the business domain, we identified articles where IS is a handmaiden of business, identifying competitive advantage and operational effectiveness (Porter 2001) of IT and IS systems and their management. More generally, this business dimension, which may include government business and provision of services, can be seen as an instrumental dimension: Information Systems research is a means to more efficient business and organisational ends.

The social dimension attempted to delineate and identify the emerging use of ICT by society outside business utility and technical development. Whereas the third dimension concerns the development of technical efficacy and innovation of the IS artefact, historically an important concern of Information Systems. Here the principal concern is not with instrumentality but with technical development, irrespective of its application.

Three further dimensions were developed empirically as a result of our pilot content analysis: 'education', 'disciplinary reflection' and 'other'. Disciplinary reflection, such as this study, may be categorised as a form of 'meta-information system'. 'Education' included training and education of IS professionals or the use of digital methods and information systems for education. 'Other' comprised a residual category for any studies that were unable to be placed in the other dimensions during the content analysis. Only eight articles were coded into the 'other' category.

\section{Diversity in Research Approach}

As shown in Appendix A, the most frequent way of investigating how IS research is conducted is by examining research methods, and differentiating between empirical vs. non-empirical research. An analysis of the studies in Appendix A showed that the three most frequently used research methods in IS are case studies, surveys, and laboratory experiments. Therefore, we coded for these three methods, and since our aim was to determine the diversity of research method, especially those methods which may be associated with the study of social phenomena, we also initially coded for action research, grounded theory, ethnography, interview methods, field experiments as well as multiple methods, content analysis and meta-analysis. Low numbers of papers in most of these categories meant we eventually collapsed several categories into an 'other' category.

Since Orlikowski \& Baroudi (1991) unsettling discovery that $96.8 \%$ of articles published in the US journals they examined were based on the positivist tradition, with only $3.2 \%$ interpretive studies, and no critical studies at all, other researchers have conducted analyses of research paradigm looking for evidence of these same three paradigms (see Appendix A). We followed this lead but added postmodern studies since these are important in IS's reference disciplines. 
Like previous researchers we also analysed research articles in terms of empirical vs non-empirical and qualitative vs quantitative research.

\section{Diversity in Research Setting}

The third major question concerns the 'where' of research; to what extent has the discipline embraced diversity in geographical regions of studies, cross-country collaboration (Hutton et al. 2011) and different research settings. Research setting might be in a business setting, a research laboratory or university or with a select group of the general public outside of these settings. Since information systems have broken out of the bounds of business we were interested to see if research setting has also diversified.

The location of research has not received attention in past analyses of IS research diversity (see Appendix A). If what is published in IS journals is following trends of globalisation then we would expect to see diversity in study region and setting. Thus, in our analysis we devised two measures to examine where research is conducted. Firstly, the geographical region where the study is undertaken, and secondly research setting which refers to the location of the study, in terms of whether it is in a business, a laboratory or a social setting.

\section{Diversity of who is Published}

Our final question concerns the 'who' of research; this dimension of research concerns diversity of authors. That is, who gets published: what countries, gender, ethnic backgrounds and so on are overrepresented in publications. The Internet and associated technologies offer the potential for increased cross-institute e-research collaboration, and the increased diversity in the use and application of information systems suggests we might expect to see more diversity in who publishes in our journals. In this research, we report on the gender and geographical region of authors.

\section{RESEARCH PROCEDURE}

For the content analysis we examined all research articles in MISQ, EJIS and AJIS from 2001 to 2010, and following Dwivedi \& Kuljis (2008) and Gallivan \& Benbunan-Fich (2007) we excluded editorials, guest editorials and book reviews. We also excluded short responses to research articles on the basis that these are more akin to editorials than full research papers, being typically only a few pages in length.

We employed and trained two research assistants to code the articles who had cataloguing and taxonomic experience as librarians. We developed a ten page coding manual to provide detailed descriptions of the types of paper we expected to see in each category. Figure 1, from the coding manual, shows diagrammatically the coded variables. These are explained next. 


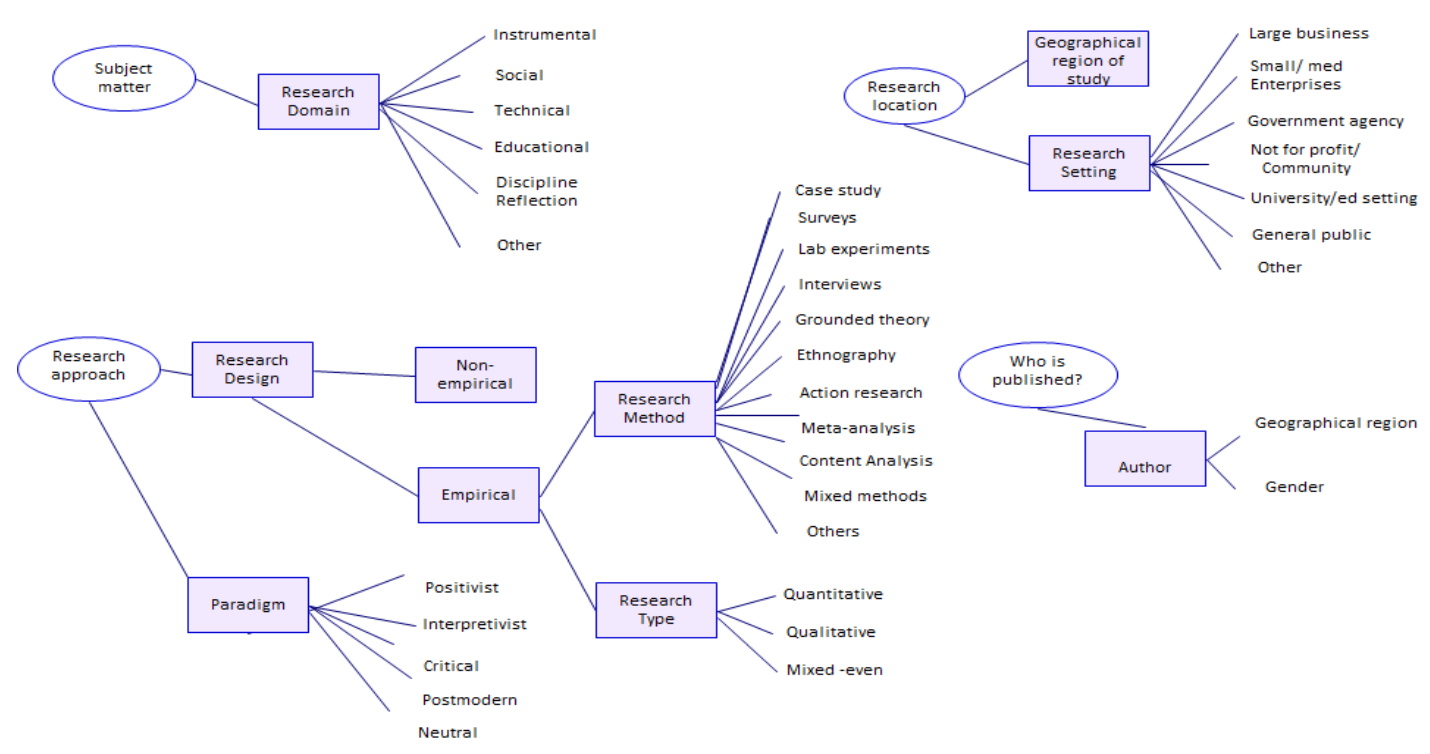

Figure 1: Coded Variables

\section{Coding for Subject Matter}

\section{Research Domain}

In analysing articles for research domain, we were interested in the underlying focus of the research rather than the topic, although in some cases there was an overlap of these constructs. For instance, ecommerce articles, while sharing the same topic, could have very different domains. In coding for research domain, articles were examined for the main focus or intent, and each article was coded as one of the following.

- Social: The principal aim of these studies is to examine the use and consequences of ICT in society and people's relationship to technology. Studies with a social focus may aim to answer questions such as 'how do people work with IS/IT?' Or, 'what is the impact or effect of IS/IT on people or societies?' Some examples of indicative topics include: technology acceptance and perception, status of women in IT, cross cultural software production and use. Topics such as social media do not necessarily make the research 'social' for our purposes. Studies of social media aimed at increasing organisational profits would be classified as instrumental while studies aimed at developing new social media systems would be classified as 'technical'.

- Instrumental: The principal research aim of these studies is to increase business efficiency, effectiveness, security and risk minimisation or other outcomes in business and business organisations. It is about making work and information systems more efficient - better management, better monitoring, better systems to 'get the job done'. This includes the use of ICT to increase the efficiency and effectiveness of the State, business or service. 
- Technical: The principal research aim of technical studies is to design and develop an IS artefact or to test a theoretical construct, practical model or algorithm where the context and application is largely irrelevant. Technical refers to the primary interest of systems information artefacts or processing where people or business is incidental to the process. Example of 'technical' topics include IS development, methods, and tools, databases, networks/telecommunications, hardware, security and Internet/computer based communication systems if technically focused.

- $\quad$ Education: The focus here is on studies covering some aspect of IS/IT education. This may include the examination or evaluation of ICT on education.

- Discipline reflection: Discipline reflection covers those articles that aimed to reflect on aspects of the current state, progress, or future of the discipline.

- $\quad$ Other: This category was used when the main focus of the article could not be identified as any of the above. Some examples of articles placed in this category include: thinking styles in science, international Information Systems security standards, standardizing and scaling in Health IS and organisational identity \& boundary objects.

All articles, whether empirical or non-empirical were coded for research domain.

\section{Coding for Location}

\section{Research Setting}

Empirical articles were also coded for research setting or location. Here we aimed to understand the context of the study. This was operationalised as determining where the study participants or representatives were from. This dimension required less interpretation than research domain as most authors declared the study context. Categories in this dimension include the following:

- $\quad$ Large business

- $\quad$ Small/medium enterprise

- Government agency

- $\quad$ Mixed studies e.g. government agency and business, or large business and SME

- $\quad$ Not-for-profit/community organisation

- University/educational setting

- General public

- Other

- $\quad$ Not applicable e.g. content analyses

\section{Geographical Location of Research}

The geographical location in which the research was undertaken was also coded for. Namely:

- $\quad$ North America

- $\quad$ United Kingdom (UK)

- $\quad$ Europe not inc. UK

- Australia

- $\quad$ New Zealand (NZ)

- Africa 
- $\quad$ Asia (incl Middle East, India)

- $\quad$ South and central America

- Unknown

- $\quad$ Multi-region

- Not applicable

To aid analysis, we grouped papers from NZ with Australia creating a category called Australasia. Similarly, because of the small numbers of papers from Africa, South and Central America we merged these regions into a category called 'Other' for analysis purposes.

\section{Coding for Research Approach}

\section{Research Paradigm}

While there exists considerable debate on the differences and subtleties of the various paradigms we take positivism to be the view that nomothetic laws underpin and explain human behaviour and these laws can best be identified through objective methods that attempt to avoid the views of the researchers that might bias the results. Interpretivists on the other hand argue that humans act according to their understandings of the world, not according to some underpinning law. The key task of the interpretivist is to identify and tease out what these often contradictory, complex and contextual understandings are. Postmodernists question not only the objective nature of our social world but apply their scepticism to the ontological status of human agent. For them the human agent is not in itself a coherent subjectivity but is itself constructed. Underpinning critical theory is the view expressed by Marx that the point of research is not to understand the world but to change it (Marx et al. 1974). For practical purposes we also included a neutral category for the rare study that attempts to survey the academic field and draws on all these perspectives. Our coders were therefore instructed to code each paper using the following guide:

- Positivist: Often identified by the presence of hypothesis testing, deductive reasoning, variables, causal relationships and the use of quantitative methods especially inferences drawn from samples to populations. We also followed Orlikowski and Baroudi's (1991) lead and included 'descriptive' papers where researchers present what they believe are objective or factual accounts of events. These 'descriptive' studies sometimes contained case studies and simple descriptive statistics.

- Interpretive: In these studies, participants' perspectives are used as the primary source of understanding of phenomena. The researcher is principally trying to discover the participants understanding of the phenomena and the meanings attached to these understandings and the actions they take as a consequence. Also phenomena are examined with respect to cultural or contextual circumstances. Interpretive studies are principally qualitative but some quantitative material may be presented.

- Critical: These studies take a critical stance towards the status-quo, often look at issues of inequality (e.g. unequal or unfair outcomes) and power and have a perspective of underpinning structural conflict between social agents. 
- Postmodern: Postmodern studies not only question the objective nature of our social world but the ontological status of the human agent. That is, postmodernists believe truth, totality (society) and the human subject to be fabrications or social constructions and the key focus of the postmodern study is to disclose this fabrication.

\section{Research Design, Method and Type}

Each article was coded as either empirical or non-empirical, and for each empirical study the research method and whether the study was qualitative, quantitative or mixed. The research methods coded for were:

$$
\begin{array}{ll}
\text { - } & \text { Case study } \\
\text { - } & \text { Surveys } \\
\text { - } & \text { Lnterviews } \\
\text { - } & \text { Field experiments } \\
\text { - } & \text { Ethnography } \\
\text { - } & \text { Meta-analysis } \\
\text { - } & \text { Grounded theory } \\
\text { - } & \text { Action research } \\
\text { - } & \text { Content analysis } \\
\text { - } & \text { Mixed methods } \\
\text { - } & \text { Other }
\end{array}
$$

Owing to the small numbers of papers in the categories action research, grounded theory, ethnography, field experiments, and meta-analysis we collapsed these methods into the Other category during analysis.

\section{Coding for who is published}

We coded both gender and region for all authors. Following Galliers and Meadows (2003) we used institutional affiliation as a proxy for the actual region of the authors.

\section{Coding procedure}

In addition to the coding manual, we also developed an Excel template to facilitate coding and asked both our research assistants to code eighteen randomly selected papers - six papers from each journal. Coders read the keywords and abstract of each paper and skimmed the introduction, conclusions, method section and references of each paper. Some articles however did require more extensive reading. We also coded the same selection of papers and then compared results to identify areas of disagreement. Some discrepancies were due to different interpretations of terms used in the coding manual and some highlighted shortcomings of the coding schema. Differences in initial coding decisions were resolved and we updated the coding manual and amended categories as appropriate. Our research assistants worked closely with each other to code the remaining articles, checking with us when in doubt. Minor amendments to the coding manual were made as necessary.

Data were imported from Excel into SPSS for data analysis. Since we coded all research articles from the three journals during the period 2001 to 2010, the collected data were population data and analysed using descriptive rather than inferential statistics. 


\section{FINDINGS AND DISCUSSION}

We organise the findings and discussion around the four dimensions of research pluralism we are investigating: what subject matter was published, where studies were conducted, how studies were conducted and who is published. To facilitate the flow of discussion, percentages are rounded to the nearest percentage point but the tables show exact figures.

\section{What Subject Matter was Published?}

Our first research question aimed at discovering if what is published in the three journals is primarily focused on business imperatives or if researchers are exploring the increasingly social context of information systems. The findings indicate that while instrumental studies still dominate in all journals, studies with a social focus are increasing.

Table 1 shows that over the study period, instrumental studies made up the largest group accounting for $45 \%$ of papers overall, with MISQ publishing a larger proportion $(55 \%)$ than the other two journals (both $41 \%$ ). Papers within the social domain were the next largest group at $38 \%$ overall. EJIS published more socially focused papers $(45 \%)$ than the other two journals which were around $33 \%$ each. Overall, research focused on discipline reflection accounted for $9 \%$ of papers, while technically focused papers accounted for 7\%. AJIS published a much higher proportion of technically focused research than the other two journals.

Looking at trends over time, Table 1 shows that overall instrumental papers have decreased from $51 \%$ (2001-2005) to $42 \%$ (2005-2010). Social papers on the other hand have increased from 33\% (2001$2005)$ to $42 \%$ (2006-2010). This suggests that these mainstream journals at least are 'following the computer out of business'. Over the study period, discipline reflection papers have trended upwards while technical papers have trended downward such that in the last five year study period they make up only $4 \%$ of the total papers published in the three journals. Educational papers make up a very insignificant proportion of the three journals surveyed.

\begin{tabular}{|c|c|c|c|c|c|c|c|}
\hline \multirow{2}{*}{\multicolumn{2}{|c|}{ Domain }} & \multicolumn{3}{|c|}{ Journal } & \multicolumn{2}{|c|}{ Period } & \multirow{2}{*}{ Total } \\
\hline & & AlS & EJIS & MISQ & & & \\
\hline \multirow{2}{*}{ Discipline reflection } & Count & 27 & 25 & 25 & 20 & 57 & 77 \\
\hline & $\%$ within Journal & $10.6 \%$ & $7.6 \%$ & $10.1 \%$ & $5.6 \%$ & $12.0 \%$ & $9.3 \%$ \\
\hline \multirow[t]{2}{*}{ Educational } & Count & 5 & 2 & 1 & 3 & 5 & 8 \\
\hline & $\%$ within Journal & $2.0 \%$ & $.6 \%$ & $.4 \%$ & $.8 \%$ & $1.1 \%$ & $1.0 \%$ \\
\hline \multirow[t]{2}{*}{ Instrumental } & Count & 106 & 136 & 135 & 183 & 194 & 377 \\
\hline & $\%$ within Journal & $41.6 \%$ & $41.3 \%$ & $54.7 \%$ & $51.3 \%$ & $40.9 \%$ & $45.4 \%$ \\
\hline \multirow[t]{2}{*}{ Social } & Count & 85 & 149 & 81 & 118 & 197 & 315 \\
\hline & $\%$ within Journal & $33.3 \%$ & $45.3 \%$ & $32.8 \%$ & $33.1 \%$ & $41.6 \%$ & $37.9 \%$ \\
\hline \multirow[t]{2}{*}{ Technical } & Count & 32 & 17 & 5 & 33 & 21 & 54 \\
\hline & $\%$ within Journal & $12.5 \%$ & $5.2 \%$ & $2.0 \%$ & $9.2 \%$ & $4.4 \%$ & $6.5 \%$ \\
\hline \multirow{2}{*}{ Total } & Count & 255 & 329 & 247 & 357 & 474 & 831 \\
\hline & $\%$ within Journal & $100.0 \%$ & $100.0 \%$ & $100.0 \%$ & $100.0 \%$ & $100.0 \%$ & $100.0 \%$ \\
\hline
\end{tabular}

Table 1: Research domain overall and by journal (excludes 8 articles coded as 'Other') 
We also analysed each journal to see if individually they followed the same trends over time. Surprisingly, Figure 2 clearly shows that from 2005-2006 onward the proportion of MISQ's publication of instrumental papers has been declining and at the same time social papers have increased, actually overtaking EJIS in the last period. Indeed, EJIS is showing an upward trend in instrumental papers during the 2007-2010 (see Figure 2) seemingly defying the commonly held view that that EJIS is more progressive or future oriented than MISQ.

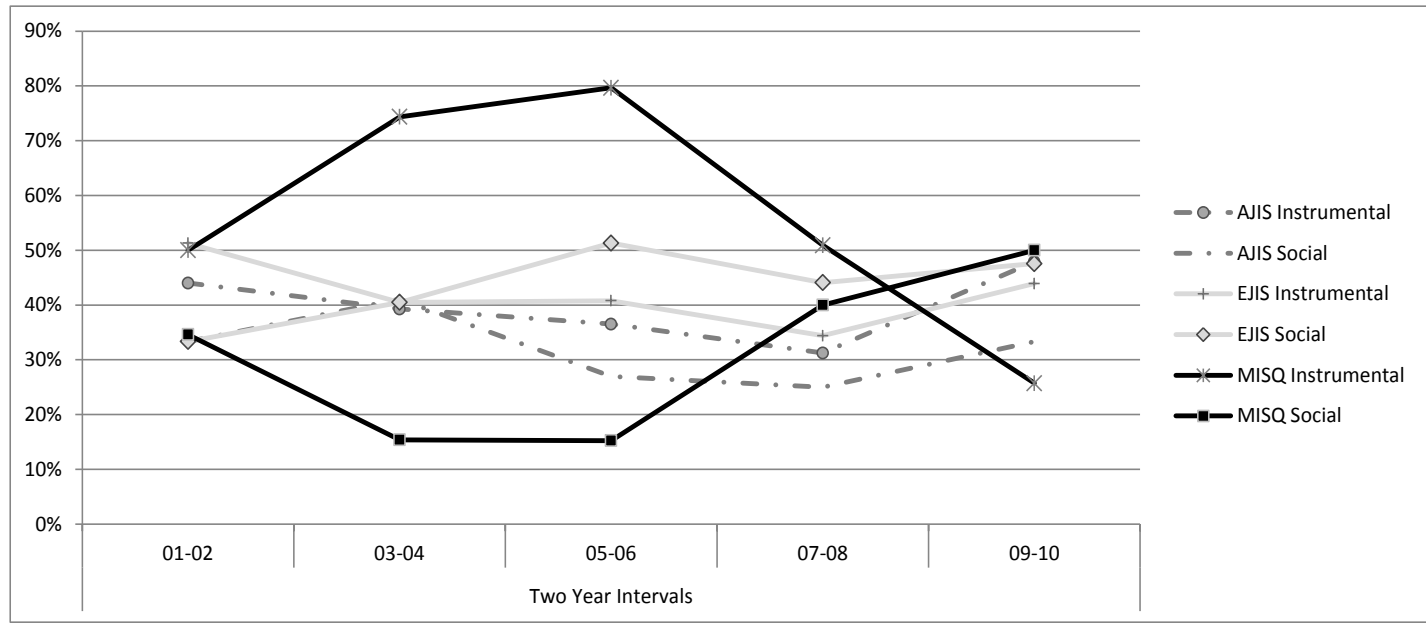

Figure 2: Trends of research domain within journal

Going against the trends of MISQ and EJIS, AJIS has, during the study period, consistently published slightly more instrumental papers than social papers.

Overall, comparing 2001-2005 and 2006-2010, we can say that the proportion of socially focused papers has increased, while instrumental papers have decreased and there are more discipline reflection papers suggesting that these journals are engaging with the expanded context of use of information systems and trying to make sense of it. The continued decline in technical papers suggests that IS leaving behind its technical roots.

\section{Where were Studies Conducted?}

\section{Research Setting}

Since information systems have broken out of the bounds of business we postulated that research setting, that is the context in which empirical research is conducted, would also show increased diversification.

Overall, we found that business settings dominate in the publications. Nearly $30 \%$ of empirical studies were set in large business (see Table 2) although there appears to be considerable difference between the journals. Of the studies published in EJIS, 37\% were set in large business; considerably more than MISQ at $25 \%$ and AJIS at $20 \%$. 


\begin{tabular}{|c|c|c|c|c|c|c|c|}
\hline \multirow{2}{*}{\multicolumn{2}{|c|}{ Setting }} & \multicolumn{3}{|c|}{ Journal } & \multicolumn{2}{|c|}{ Period } & \multirow[b]{2}{*}{ Total } \\
\hline & & Alls & EJIS & MISQ & 2001-2005 & 2006-2010 & \\
\hline \multirow[t]{2}{*}{ General public } & Count & 10 & 16 & 24 & 14 & 36 & 50 \\
\hline & $\%$ within Journal & $8.3 \%$ & $6.3 \%$ & $13.7 \%$ & $6.6 \%$ & $10.7 \%$ & $9.1 \%$ \\
\hline \multirow[t]{2}{*}{ Government agency } & Count & 13 & 24 & 7 & 20 & 24 & 44 \\
\hline & $\%$ within Journal & $10.7 \%$ & $9.4 \%$ & $4.0 \%$ & $9.4 \%$ & 7.1\% & $8.0 \%$ \\
\hline \multirow[t]{2}{*}{ Large business } & Count & 24 & 93 & 43 & 52 & 108 & 160 \\
\hline & $\%$ within Journal & $19.8 \%$ & $36.6 \%$ & $24.6 \%$ & $24.5 \%$ & $32.0 \%$ & $29.1 \%$ \\
\hline \multirow[t]{2}{*}{ Mixed } & Count & 7 & 46 & 39 & 38 & 54 & 92 \\
\hline & $\%$ within Journal & $5.8 \%$ & $18.1 \%$ & $22.3 \%$ & $17.9 \%$ & $16.0 \%$ & $16.7 \%$ \\
\hline \multirow[t]{2}{*}{ NFP/Community } & Count & 6 & 17 & 8 & 13 & 18 & 31 \\
\hline & $\%$ within Journal & $5.0 \%$ & $6.7 \%$ & $4.6 \%$ & $6.1 \%$ & $5.3 \%$ & $5.6 \%$ \\
\hline \multirow[t]{2}{*}{ SME } & Count & 30 & 24 & 15 & 41 & 28 & 69 \\
\hline & $\%$ within Journal & $24.8 \%$ & $9.4 \%$ & $8.6 \%$ & $19.3 \%$ & $8.3 \%$ & $12.5 \%$ \\
\hline \multirow[t]{4}{*}{ University } & Count & 31 & 34 & 39 & 34 & 70 & 104 \\
\hline & $\%$ within Journal & $25.6 \%$ & $13.4 \%$ & $22.3 \%$ & $16.0 \%$ & $20.7 \%$ & $18.9 \%$ \\
\hline & Count & 121 & 254 & 175 & 212 & 338 & 550 \\
\hline & $\%$ within Journal & $100.0 \%$ & $100.0 \%$ & $100.0 \%$ & $100.0 \%$ & $100.0 \%$ & $100.0 \%$ \\
\hline
\end{tabular}

Table 2: Research setting overall by journal and period (excludes 65 'Not Applicable' and 30 'Other' papers).

In addition, most of the 'mixed' studies, which accounted for $17 \%$ of studies overall, also included a large business (either large business and SMEs, or large business and government department). MISQ published $22 \%$ of these mixed studies, EJIS $18 \%$ and AJIS only $6 \%$. SMEs were the setting of only $13 \%$ of studies overall, with a large difference between AJIS (25\%) and the other two journals both at around 9\%. In contrast, research set in government agencies, not-for-profit or community organisations, and the general public together account for $23 \%$ overall in the publications. University based studies were the second largest single group with $19 \%$ of studies overall. This may be because of the convenience factor; researchers often use student cohorts for data collection purposes and universities also provide venues for lab studies. However, there were differences between the journals. EJIS published less research set in universities (13\%) compared to AJIS (26\%) and MISQ (22\%).

We were also interested in understanding how study setting has changed overtime. The most noteworthy trends are those involving large business and SME settings. Both these settings show considerable difference between the first period (2001-2005) and the second time period (2006-2010). During 2001-2005, research set in large business accounted for only $25 \%$ of studies overall but by 2006-2010 the figure is 32\%. It would appear that these gains have been at the expense of research set in SMEs since during 2001-2005 SMEs made up 19\% of the studies but by 2006-2010 the figure had declined to $8 \%$ (see Table 2). This decline is consistent with the findings of Powell and Woerndl (2008) regarding the falling research interest in SMEs.

\section{Geographical Region of Study}

We also analysed the region in which each study was located since we conjectured that if Information Systems is following trends of globalisation then we would expect to see some evidence of increased diversity in study regions. As Table 3 shows, overall North American studies make up the largest proportion with over a third of all studies, followed by European studies (including the UK) at $23 \%$. 
Australasian studies make third place with $19 \%$ of studies. South \& Central America and Africa have only been the research setting of 6 papers in ten years $(.04 \%$ each) so we combined them into the category 'Other/Unknown'. Looking at the individual journals, EJIS has the greatest diversity of study regions with 38\% focused on UK and Europe, 33\% focused on North America, 16\% focused on Asia and Australasia. Both MISQ and AJIS appear largely parochial with around 70\% of studies conducted locally and on this basis one may question their international scope.

\begin{tabular}{|c|c|c|c|c|c|c|}
\hline & & & \multicolumn{3}{|c|}{ Journal } & \multirow[b]{2}{*}{ Total } \\
\hline & & & AJIS & EJIS & MISQ & \\
\hline \multirow[t]{14}{*}{ Study Region } & \multirow[t]{2}{*}{ Asia (incl Middle East, India) } & Count & 9 & 29 & 14 & 52 \\
\hline & & $\%$ within Journal & $6.7 \%$ & $10.9 \%$ & $7.4 \%$ & $8.9 \%$ \\
\hline & \multirow[t]{2}{*}{ Australasia } & Count & 95 & 12 & 3 & 110 \\
\hline & & $\%$ within Journal & $70.9 \%$ & $4.5 \%$ & $1.6 \%$ & $18.7 \%$ \\
\hline & \multirow[t]{2}{*}{ Europe not inc. UK } & Count & 10 & 55 & 16 & 81 \\
\hline & & $\%$ within Journal & $7.5 \%$ & $20.8 \%$ & $8.5 \%$ & $13.8 \%$ \\
\hline & \multirow[t]{2}{*}{ UK } & Count & 5 & 45 & 2 & 52 \\
\hline & & $\%$ within Journal & $3.7 \%$ & $17.0 \%$ & $1.1 \%$ & $8.9 \%$ \\
\hline & \multirow[t]{2}{*}{ North America } & Count & 4 & 86 & 130 & 220 \\
\hline & & $\%$ within Journal & $3.0 \%$ & $32.5 \%$ & $69.1 \%$ & $37.5 \%$ \\
\hline & \multirow[t]{2}{*}{ Multi-region } & Count & 9 & 30 & 17 & 56 \\
\hline & & $\%$ within Journal & $6.7 \%$ & $11.3 \%$ & $9.0 \%$ & $9.5 \%$ \\
\hline & \multirow[t]{2}{*}{ Other/Unknown } & Count & 2 & 8 & 6 & 16 \\
\hline & & $\%$ within Journal & $1.5 \%$ & $3.0 \%$ & $3.2 \%$ & $2.7 \%$ \\
\hline \multirow{2}{*}{\multicolumn{2}{|c|}{ Total }} & Count & 134 & 265 & 188 & 587 \\
\hline & & $\%$ within Journal & $100.0 \%$ & $100.0 \%$ & $100.0 \%$ & $100.0 \%$ \\
\hline
\end{tabular}

Table 3: Study region by journal

We also examined the trends over time for each journal and plotted the major changes in Figure 3 below. This analysis shows that there has been a large increase of North American based studies published in EJIS (21\% during 2001-2005 up to 38\% during 2006-2010) and a corresponding dip in studies set in North America published in MISQ (80\% down to 64\%). The other noteworthy trend in EJIS is a decrease in publication of studies undertaken in the UK, down from 27\% 2001-2005 to $12 \%$ in 2006-2010, while at the same time there is an increase in studies located in continental Europe $(15 \%$ to $24 \%)$.

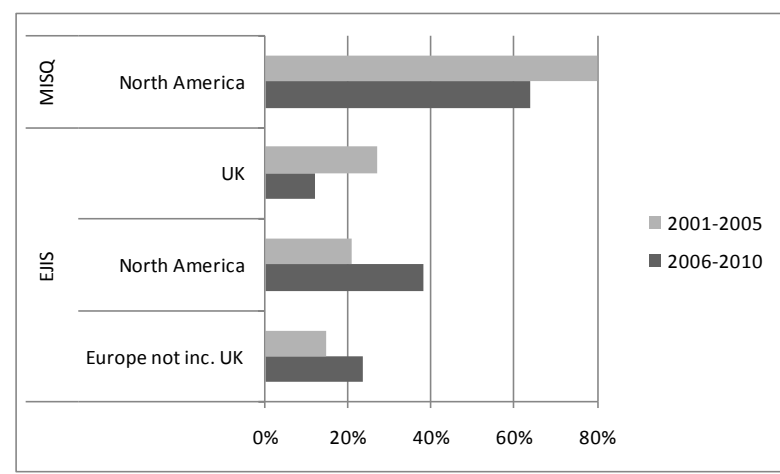

Figure 3: Study regions in MISQ and EJIS showing key changes only 


\section{How were Studies Conducted?}

\section{Research Paradigm}

If Information Systems is to claim research pluralism we would expect to see a good mix of papers using critical, interpretivist, positivist and postmodern paradigms within its journals. However, Table 4 shows that overall positivist approaches, at $61 \%$ of all studies, still dominate while interpretivist studies make up only $30 \%$ overall. Critical and postmodern studies have made hardly any inroads into the publications we studied. Comparing the journals, MISQ published significantly more positivist research (81\%) compared to EJIS (51\%) and AJIS (56\%). EJIS leads the way with interpretivist research at $41 \%$ compared to MISQ's at $12 \%$ and AJIS's at $32 \%$. Notably MISQ published no critical papers during the study period.

\begin{tabular}{|c|c|c|c|c|c|c|c|}
\hline \multirow{2}{*}{\multicolumn{2}{|c|}{ Paradigm }} & \multicolumn{3}{|c|}{ Journal } & \multicolumn{2}{|c|}{ Period } & \multirow[b]{2}{*}{ Total } \\
\hline & & AlS & EJIS & MISQ & 2001-2005 & 2006-2010 & \\
\hline \multirow[t]{2}{*}{ Critical } & Count & 8 & 12 & 0 & 12 & 8 & 20 \\
\hline & $\%$ within Journal & $3.1 \%$ & $3.6 \%$ & $.0 \%$ & $3.3 \%$ & $1.7 \%$ & $2.4 \%$ \\
\hline \multirow[t]{2}{*}{ Interpretivist } & Count & 83 & 136 & 30 & 123 & 126 & 249 \\
\hline & $\%$ within Journal & $32.2 \%$ & $41.0 \%$ & $12.0 \%$ & $34.3 \%$ & $26.3 \%$ & $29.7 \%$ \\
\hline \multirow[t]{2}{*}{ Neutral } & Count & 20 & 14 & 17 & 22 & 29 & 51 \\
\hline & $\%$ within Journal & $7.8 \%$ & $4.2 \%$ & $6.8 \%$ & $6.1 \%$ & $6.0 \%$ & $6.1 \%$ \\
\hline \multirow[t]{2}{*}{ Positivist } & Count & 145 & 169 & 201 & 199 & 316 & 515 \\
\hline & $\%$ within Journal & $56.2 \%$ & $50.9 \%$ & $80.7 \%$ & $55.4 \%$ & $65.8 \%$ & $61.4 \%$ \\
\hline \multirow[t]{2}{*}{ Postmodern } & Count & 2 & 1 & 1 & 3 & 1 & 4 \\
\hline & $\%$ within Journal & $.8 \%$ & $.3 \%$ & $.4 \%$ & $.8 \%$ & $.2 \%$ & $.5 \%$ \\
\hline \multirow{2}{*}{ Total } & Count & 258 & 332 & 249 & 359 & 480 & 839 \\
\hline & $\%$ within Journal & $100.0 \%$ & $100.0 \%$ & $100.0 \%$ & $100.0 \%$ & $100.0 \%$ & $100.0 \%$ \\
\hline
\end{tabular}

Table 4: Paradigm by journal and period

During the last five-year period, Table 4 also shows that positivism on average has increased by $10 \%$ in the journals while there has been a decrease in interpretive research of around eight percentage points. Analysing trends by journal however, reveals that most of the change has occurred in EJIS and AJIS. EJIS averaged 50\% interpretive research in the first period but this decreased to $36 \%$ during the second period (see Figure 4). At the same time, EJIS increased the publication of positivist studies from $42 \%$ to $55 \%$. AJIS showed a similar increase in positivist studies and a corresponding decrease in interpretive studies during the same period (see Figure 4).

So while MISQ has maintained a fairly constant proportion of positivist to interpretive studies over the two study periods, both EJIS and AJIS appear to be moving in a more conservative direction, publishing more positivist and less interpretive studies over the last five year period.

\section{Research design, type, and method}

Each article was also coded as either empirical or non-empirical. Non-empirical studies include work such as theory development and literature reviews. Overall, empirical research at $77 \%$ outstrips nonempirical research at $23 \%$ by a wide margin. There is also a marked difference between AJIS and the other two journals. During the period 2001-2010, AJIS published 59\% empirical papers compared to EJIS and MISQ at approximately $85 \%$ (see Figure 5). If non-empirical studies serve to develop 
theory and new concepts as suggested by Chen \& Hirschheim (2004) and Avison et al (2008) we would expect to see an increase in non-empirical work as researchers grapple with the new research problems in the age of ubiquitous information systems. However, trends over the two 5 year periods show the proportion of empirical to non-empirical research remained fairly constant.

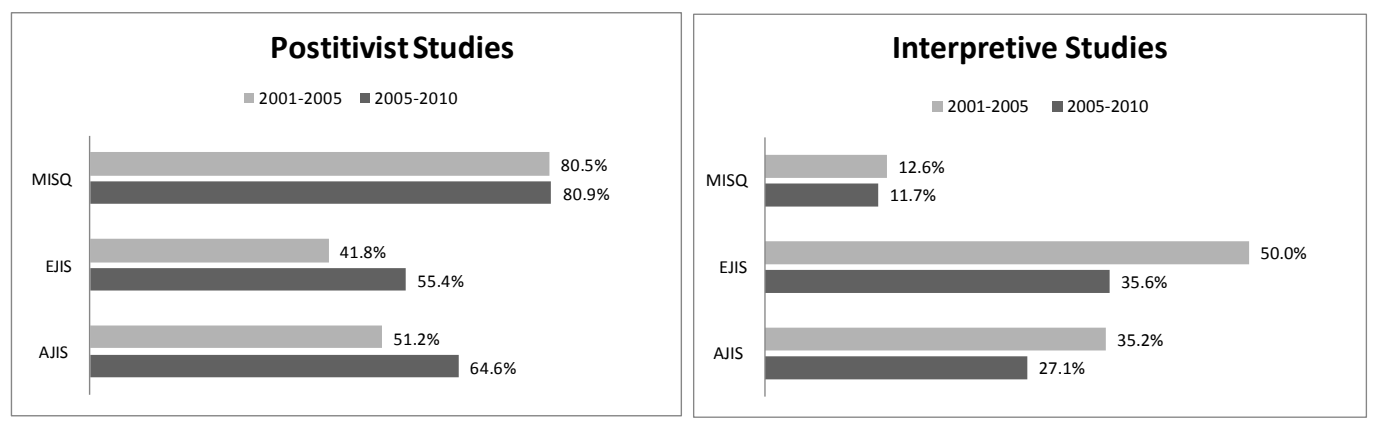

Figure 4: Paradigm trends by journal - positivist and interpretive only

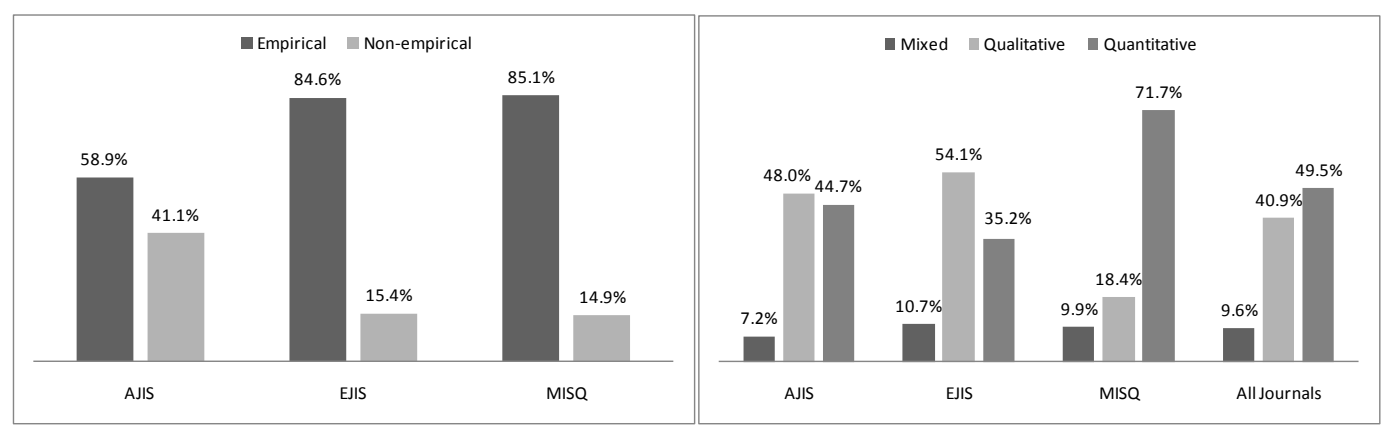

Figure 5: empirical vs non-empirical

Figure 6: Study type by journal and in total

For each empirical study we also analysed whether the study used primarily qualitative, quantitative or mixed methods. We found that overall during 2001-2010 quantitative approaches where used in $50 \%$ of studies, outnumbering qualitative approaches at $41 \%$ and mixed methods at $10 \%$ (see Figure $6)$.

However, looking at the individual journals it is clear that MISQ publishes a much greater proportion of quantitative papers (72\%) than EJIS (35\%) and AJIS (45\%) (see Figure 6). Conversely, EJIS $(54 \%)$ published more qualitative work than AJIS (48\%) and much more than MISQ (18\%).

In terms of trends, Figure 7 MISQ shows a small upward trend in quantitative work (from $70 \%$ in 2001-2005 to $73 \%$ in 2006-2010) and a corresponding small decrease in qualitative studies (from $22 \%$ in $2001-2005$ to $17 \%$ in 2006-2010). This is particularly interesting in light of MISQ's increase in publishing research within the social domain. Although EJIS has published more qualitative 
papers than either MISQ or AJIS it is actually trending downward from 62\% in 2001-2005 to 50\% in 2006-2010 while showing a corresponding increase in quantitative work during the same period $(28 \%$ in 2001-2005 to $39 \%$ in 2006-2010). AJIS has maintained a fairly constant proportion of qualitative to quantitative papers over the two time periods.

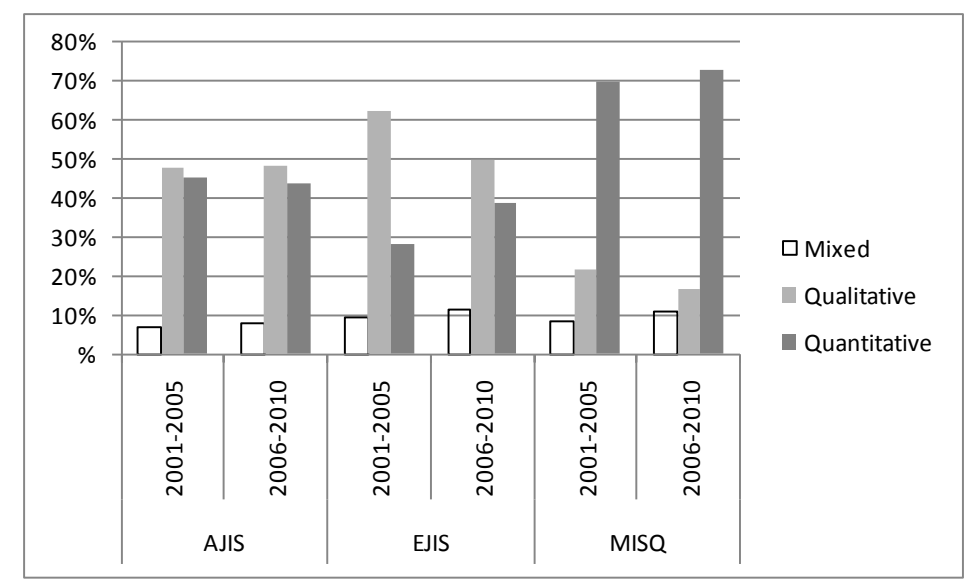

Figure 7: proportion of research types over time

In terms of research method, our findings, show that case studies $(29.8 \%)$, surveys $(27.6 \%)$ and lab experiments $(9.8 \%)$ are the top three methods used although the proportion varies across the three journals. Surveys were the most used method in MISQ papers (34\% of studies) and AJIS (29\% of studies), while case studies were the most popular method in EJIS (42\% overall).

As explained earlier, we initially coded for a wide range of research methods looking particularly for methods associated with the study of social phenomena (see section 3.3). However, since the categories action research, grounded theory, ethnography, field experiments, and meta-analysis yielded only a small number of papers (less than $5 \%$ each of the total) we collapsed these methods into a category called Other.

Examining trends of the top three methods in each journal (see Figure 8) shows that both EJIS and MISQ show an upward trend in publishing survey-based research and EJIS a corresponding drop in case study research. MISQ also published more lab experiments in the second study period while EJIS and AJIS published less. Apart from the small rise in case study research evidenced in AJIS, there is no increase in methods we would associate with the study of social phenomena or a new research area since 'Other' methods accounted for 13.7\% of total methods during 2001-2005 and $16.5 \%$ during 2006-2010. 


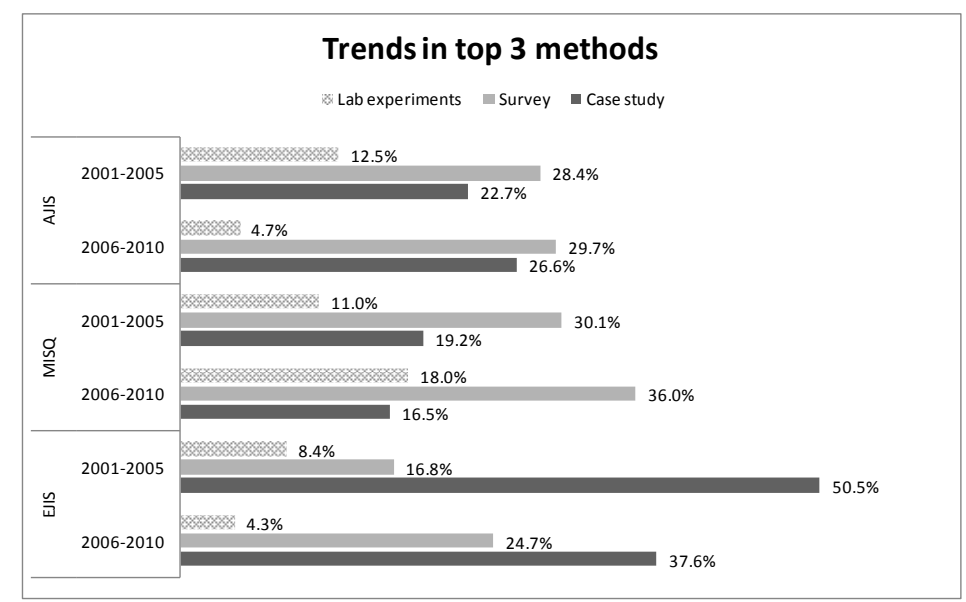

Figure 8: Top three research methods trends

In summary, MISQ is still dominated by positivist, quantitative, survey research. EJIS leads the way in interpretive, qualitative and case study research although it appears to be trending towards more conservative empirical methods. AJIS is more eclectic, publishing more non-empirical work and a more even proportion of qualitative and quantitative work than the other two journals.

Socially focused research has increased over the past decade and as of 2010 is showing around the same proportion as instrumental studies. However, socially focused studies are being researched using the same type of research methods as instrumental studies. Further analysis showed for instance, that overall case studies were used in approximately $31 \%$ of both types of studies, and surveys in around $30 \%$ of cases. Lab experiments were the preferred method of $7.6 \%$ of instrumental studies and $8.6 \%$ of social studies. Comparing research domain with research paradigm we find that interpretivism comprises $30 \%$ of instrumentalist studies and $42 \%$ of social studies. Positivism comprises the balance $(70 \%)$ of instrumentalist studies and over half of social focussed studies. Finally, comparing research domain with research type shows that only $45 \%$ of social research is approached using qualitative methods.

\section{Source of Research: Who Publishes?}

Our final question explored who is published. In particular, we analysed the gender, geographical region (as indicated by affiliation) and academic home department of authors.

\section{Author Gender}

The findings show a significant gender imbalance amongst authors. Overall $28 \%$ of the total 1836 authors are women and a slightly higher proportion (32\%) of first authors are women. MISQ averaged $25 \%$ female authorship, compared with EJIS at $26 \%$ and AJIS at $37 \%$ (see Figure 9). Avison et al (2008) report an even greater gender imbalance in the Information Systems Journal where the percentage of female authors in publications between 2003 to 2007 was around 20\%. In light of Avison et al's (2008) findings we also analysed the trends in the gender of authors over time. 
We found that overall the proportion of female authors was almost identical across the two time periods 2001-2005 and 2006-2010.

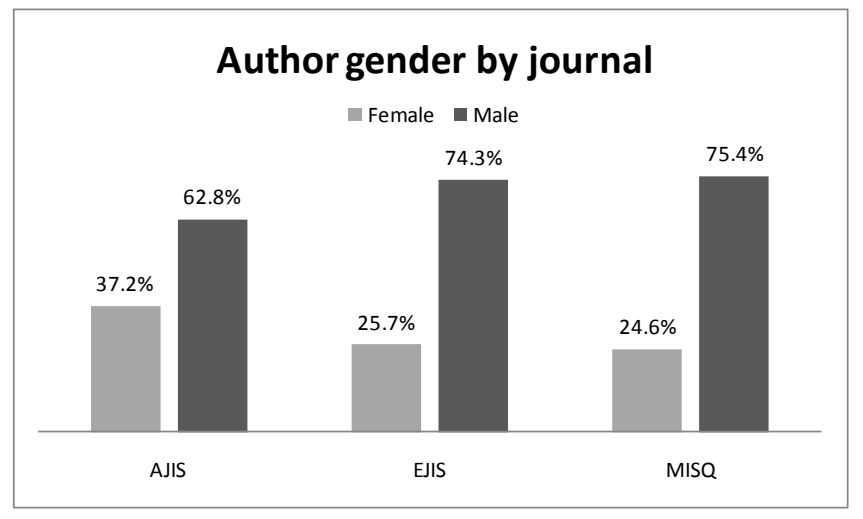

Figure 9: Author gender by journal (excludes 89 authors where gender could not be determined)

Next, we looked at whether women publish differently to men. Differences in research focus and paradigm were evident. Men were more likely to publish positivist papers (66\% men compared with $52 \%$ women) and instrumental papers (47\% men compared with $40 \%$ women).

\section{Author Region}

The findings for the geographical region of the authors for the three journals show that approximately $42 \%$ of authors overall are from North America (see table 5 below).

\begin{tabular}{|ll|r|r|r|r|}
\hline & & \multicolumn{2}{|c|}{ Journal } & \multirow{2}{*}{ Total } \\
\cline { 2 - 5 } & AJIS & \multicolumn{1}{|c|}{ EJIS } & MISQ & \multicolumn{1}{|c|}{28} \\
Asia (incl Middle East, India) & Count & 71 & 48 & 147 \\
& \% within Journal & $5.2 \%$ & $9.1 \%$ & $7.9 \%$ & $7.6 \%$ \\
\hline Australasia & Count & 394 & 56 & 24 & 474 \\
& \% within Journal & $73.2 \%$ & $7.2 \%$ & 0 & $24.6 \%$ \\
\hline Europe not inc. UK & Count & 44 & 195 & 51 & 290 \\
& \% within Journal & $8.2 \%$ & $24.9 \%$ & $8.4 \%$ & $15.1 \%$ \\
\hline North America & Count & 40 & 293 & 468 & 801 \\
& \% within Journal & $7.4 \%$ & $37.4 \%$ & $77.5 \%$ & $41.6 \%$ \\
\hline Other/Unknown & Count & 7 & 3 & 5 & 15 \\
& \% within Journal & $1.3 \%$ & $.4 \%$ & $.8 \%$ & $.8 \%$ \\
\hline UK & Count & 25 & 165 & 8 & 198 \\
& \% within Journal & $4.6 \%$ & $21.1 \%$ & $1.3 \%$ & $10.3 \%$ \\
\hline & Count & 538 & 783 & 604 & 1925 \\
& \% within Journal & $100.0 \%$ & $100.0 \%$ & $100.0 \%$ & $100.0 \%$ \\
\hline
\end{tabular}

Table 5: Author regions 
Further, 78\% of MISQ authors are North American and surprisingly 37\% of EJIS authors are also from North America (see table 5). Further exploration of the EJIS data for regions of first author reveals the greatest change has occurred in the last 4 years, with North American authors increasing from around 15\% in 2001 and 2002 to nearly half of all publications (47.6\%) by 2009 and 2010.

The only other straight-line trend in the data is again in EJIS which has seen a steady decrease in first author publications from UK authors falling, from nearly half all publications in 2001 and 2002 (48.7\%), to less than ten per cent (8.5\%) by 2009 and 2010 .

The changes in region-authored publications may help to explain the changes in the research focus and research paradigm of EJIS and MISQ respectively. With respect to EJIS, the decline in UK authored publications and the rise in North American authored publications may explain the increase in positivist research in EJIS. Seventy per cent of North American first authored publications published in EJIS were positivist, compared with only 13\% of UK first authored publications. On the other hand, in MISQ, $42 \%$ of interpretivist publications had European first authors, compared with only $9 \%$ of North American first authors. Fifty three per cent of social research domain papers had European first authors compared with $30 \%$ of North American first author publications.

\section{FURTHER REFLECTIONS}

Taken as a whole, the journals' record is not a ringing endorsement for change and diversity of research outcomes. Positivist and instrumentalist research predominates across the decade. Indeed, positivist studies have trended upward over the ten-year period from around 55\% in 2001-2002 to nearly $74 \%$ in 2009-2010. All three journals have published very little postmodern or critical theory research (see table 4). Significantly, interpretive studies, while far better represented in IS than postmodern and critical theories, actually fell over the period (see table 4).

On the other hand, our analysis shows that overall socially focused research has increased over the past decade from 33\% in 2001-2005 to 42\% in 2006-2010 and as of 2010 is showing around the same proportion as instrumental studies. Over the period we have seen a small rise in reflective studies at the expense of a similar fall in technical studies. There was little change over the period in the proportion of empirical to non-empirical studies. With respect to research settings the picture is not especially clear-cut. There was a small increase in the research setting of the general public but this was offset by a similar decline in the studies taking place in community settings. The two major changes in research setting were seen in the business arena with a large decline in the study of small business and a corresponding increase in the study of large businesses. With respect to methods, the most popular research method, quantitative surveys, increased its popularity in publication.

This suggests that there has been a modest and most likely conservative response in the publications to the changing nature and penetration of information systems into the social world. It is modest to the extent that the rapid rise of ubiquitous computing and the digital native in the past decade represents a new and significant social phenomenon, in contrast to the relative stability in the strategic direction of business and IS.

The conservatism is suggested by the decline of diversity in methodology. Interpretivism has fallen and the publication of postmodernism and critical theory is negligible. Social focus has increased but the methodological paradigm remains conservative. At face value this is surprising as interpretivism 
is well represented in the social science research literature and postmodern and critical theory enjoy considerable status and popularity in the social sciences. One would expect that as information systems research grapples with the penetration of information systems into the social world that the discipline would draw upon a greater breadth of current social sciences methodologies.

To sum up regarding who publishes, we see little change in the balance of gender over the ten year period with a little over one in four publications including a woman author. There is evidence to suggest that this reflects the number of women academics (Lamp 2007). It is nevertheless a little disheartening not to see any improvement in this number.

With respect to author region, it can be argued that of the three journals surveyed, only one is international in perspective - EJIS. AJIS and MISQ predominantly publish authors of their own region. EJIS published around 54\% of non-European authors while AJIS published 25\% of nonAustralasian and MISQ published around 20\% non-North American authors. The question becomes one of whether this is a reflection of submissions from regions or some form of editorial gatekeeping. The question must remain open and we suspect different answers for each of these journals. With respect to EJIS, there was a major increase in North American authors, more or less at the expense of British authors following the appointment of a North American editor and a strong policy of internationalising the journal.

Certainly, it would appear that AJIS and MISQ have a long way to go should they wish to become truly international in input, if not perspective. It is nevertheless a moot point as to the degree to which IS journals can and should be international. This is at least partly due to the nature of the discipline itself.

Unless one takes an extreme nomothetic view of IS, one can expect contextual and regional matters to play a significant role. Indeed, even should one consider that IS is or can be highly nomothetic, the regional context of the study significantly weakens whatever nomothetic lessons that can be drawn from the study and the interest of the regional readership. For example, a TAM study in the US is likely to be of greater general interest in the US than one in New Zealand, Taiwan, India or Zimbabwe. Van Halen and Henken (2012) in their international survey of demographers found that researchers focussed less on regional and policy matters in order to increase their publications in high ranking journals. This is supported by the study of journal titles by Jaques and Sabire (2010) who found that, among other things, the mention of a region in the title lessened citations in medical journals. What might interest the general reader of such studies outside of his or her region is the cultural or contextual proximity of the region to their own or the novelty of methods employed in the study.

This matter of regional context appears to be completely overlooked in the various rankings of journal quality. The problem of regional context may also be compounded by research in the social world and the methodologies of non-positivist research and the cross fertilisation of ideas and approaches across the continents will remain a challenge.

Finally we come to consider the reasons for the tepid changes we have described. We propose three principal and interlocking reasons: 


\section{The Nature of Leading Journals}

To begin, it may be argued that we are looking in the wrong place for innovation in Information Systems. It may be the case that the top journals are unsuited to innovation and picking up rapid change. There has been an explosion of new journals in Information Systems over past decade (Lamp 2011 p.4) and it may be these new journals that are publishing innovation. For as much as we might wish that these top journals reflect the acme of research in the discipline, they probably more accurately reflect exemplary research at the centre of the discipline. That is to say, these flagship journals and other highly ranked journals may define an orthodox, mainstream view of what to research and how to research it (Adler et al. 2009). This position is quite consistent with Kuhn's (1970) view of the development of normal science and is probably inevitable in any ongoing community of practice (Latour et al. 1986; Wenger 1999).

It is possible however that the slowness seen in publishing in the social area may be due to a necessary lag between identifying a research project, undertaking it and getting it published. This is undoubtedly true and brings into question the appropriateness of journals in rapidly changing areas such as Information Systems. Our concern is that if journals prove to be averse and slow to change, this may influence the discipline, particularly with the rise of the importance of top ranked journals rather than conferences or social media publications.

The influence of North American information systems

On the basis of our study, one cannot but be impressed by the sheer quantity of publications by North American authors. This may well reflect the industriousness, quality, funding and number of North American scholars. However, it may well have an unintended homogenising effect on IS that tends to undermine ideographic and contextual research as well as different research cultures and approaches. Such a point rests on the notion that there are legitimate cultural differences in IS across the globe in terms of interests, writing styles, traditions and approaches. Our study does suggest that different regions do differ in the use of different methodologies, possibly the most well-established of the indicators of diversity.

Sheer numbers of publications may lead researchers to the view that there is an orthodox position which they need to emulate (Van Halen and Henken, 2012). In the case of IS there is a real possibility that this orthodoxy is increasingly becoming a North American one. Our evidence suggests that the weight of numbers of North American research may be affecting EJIS. Rather than EJIS diversifying in response to the changes over the past decade, this acclaimed diverse and progressive IS publication (Wilcocks et al. 2008), appears to be moving towards positivism, instrumentalism and big business and if anything beginning to converge with the profile of MISQ (see Figure 4 and Table 1). An explanation for the convergence of research domain and the movement towards the North American positivist and instrumentalist position is that (a) North American scholars are increasingly targeting EJIS, possibly in response to the AIS senior scholars forum 2006 recommending the inclusion of EJIS in its list of A journals. (b) the emulation of successful publication strategies and the adoption of the cultural research practices and interests of North American information systems by authors and the underplaying of the particular circumstances of IS in their own region or (c) some combination. 
North American dominance may unintentionally represent a form of academic globalisation and homogenisation and the major journals may become less interested in publishing contextual matters, especially outside the interests of the dominant research and readership region, North America.

The conservative nature of the discipline itself

Finally, the discipline itself was borne out of the problems of business with information technology. This led to IS identifying itself with business and its instrumental needs and as a discipline it has trained and attracted people to these ends. Critical theory and postmodernism are unlikely to feature prominently in this mindset. Moreover, universities themselves are becoming increasingly instrumental in character and impact is often considered in terms of business interest.

These three factors: the nature of flagship journals, the influence of North America and the conservatism of the discipline may provide a significant brake on diversity and the response in IS to a changing world and an isolation from real world problems. However, it seems that while we may have identified possible reasons for what we describe as a tepid diversity in the journals and response to change, what may drive this process and have greater implications is the journal ranking process itself and the heightened need of the IS researcher to publish in the higher ranked journals. This may be the key driver of this process.

As we have described above, the top journals have a natural tendency towards the mainstream and orthodox. To get published in such journals, the researcher with an eye to his or her career and survival as an academic will be tempted to study in the mainstream, using the orthodox repertoire of methods and if we are correct, studying such issues and with approaches that are popular in North America. One may suggest that research has been ever thus with researchers looking to the centre (in our case North America) for guidance. However, previously the non-mainstream journals provided an outlet for alternatives. Now, they are by definition of 'lower quality' and publications in such journals are discouraged or discounted. Orthodoxy is reinforced.

There is now the real fear that important problems will be neglected for safe problems investigated in an orthodox manner as a result of an orthodoxy and increased emphasis on publishing in the top journals (Powell \& Woerndl, 2008; Lincoln, 2012; Özbilgin, 2009). Essentially, researchers will be taking the advice they give their PhD students: to pick a topic that is likely to succeed and at the very least won't threaten the examiners if it doesn't expressly flatter them.

Powell and Woerndl (2008) in their provocatively titled article, 'Time to stop researching the important things?' have shown that there are real consequences for working in new or small areas of research. Such research garners fewer citations than those working in a more fashionable and orthodox area. They show that articles that cite the Technology Acceptance Model (TAM) have a higher citation index than those that cite Small Medium Enterprises (SMEs). This is consistent with our findings of the decline in SME research in our flagship journals. It is also consistent with Van Dalen and Henken's (2012) findings that more context free theoretical work such as TAM is being published at the expense more applied and thus localised work such as SME research.

Özbilgin (2009) goes further in the potential or actual effects of the journal ranking system on publications. Referring to the field of business and management studies, Özbilgin supports the view that such systems stifle innovative scholarship and research and forcefully argues "the current hegemonic order in journal publishing encourages cloning and inbreeding. Even more worrisome is 
an engagement with questions of marginal relevance. This trend presents a tyrannical challenge against ethical, purposeful, meaningful, and engaged scholarship."

Within our own discipline, Chen and Hirschheim (2004) identified similar pressures at work to discourage interpretivist work, observing that:

While under the pressure of tenure and promotion, researchers would tend to choose a less time consuming approach - positivism - to avoid perishing. This might help explain why interpretive influences are still marginal and likely to continue to be this way. As such, for a pluralist research tradition to be established, both the publication and tenure and promotion systems might need some modifications. The reason that most researchers employ a less time- consuming approach is because for tenure and promotion, the quantity of publications counts.

The less time consuming the approach, the more productions are possible; the more productions, the better the chance for tenure and promotion. While the tenure and promotion system values the quality of publications as well, it is difficult to get tenure at a good school without suitable numbers of publications. In the existing system, researchers are more concerned about how to get a research project published rather than asking significant research questions. Many research papers fail to address meaningful issues as they are too difficult and take too long to publish (Chen and Hirschheim, 2004:225).

Our findings are consistent with this view. Chen and Hirschheim's view is supported by one of the doyennes of qualitative research, Yvonne Lincoln (2012) where she argues that qualitative research and research that threatens the status quo is being silenced through lack of funding and lack of publishing outlets into the high ranking areas.

\section{CONCLUSION}

We found at best modest change in the three leading journals we studied in the face of what we consider to be a massive change and penetration of IS into the social sphere. While modest change may be expected in the top journals it does not auger well for the discipline in the light of the increased emphasis on journal rankings that in all likelihood reinforce orthodoxy.

We suggest that cultural or regional diversity in terms of research interests; context and methodology may be under threat, as may be research that challenges the status quo. If this is correct, then the growth of the discipline is stifled right at the very time it could well become the central discipline of information in society and business.

This rather gloomy conclusion for the discipline contrasts with the sunny disposition of IS in the social world. However, at the very least, seeing this issue, even somewhat tentatively suggests firstly further research to determine the existence, extent and power of this homogenising and conservative force. It also provides the opportunity for government and university policy makers, particularly in non-dominant regions, to consider the need to adjust their journal rankings to ensure diversity and inclusion.

It would be remiss at this point were we not to suggest some recommendations for the development of diversity in these and other journals. It is here that the editorial boards of journals may well have the most important role. This has been previously recognised. For instance, Allen Lee's work as senior 
editor and later MISQ editor-in-chief was influential in promoting methodological pluralism in the discipline (Chen et al. 2004). The influence of the chief editor may also be seen where in 2005, Carol Saunders became editor MISQ and brought a new "diamond cutter" approach to reviewing papers and called for a dramatic change in approach at MISQ. Significant in this was an opening up of the reviewing pool and a focus on assisting authors, rather than being gatekeepers. It is possible that these changes ushered in by Saunders led to the change in research content in MISQ post 2005. Similarly, we note the recent call by EJIS editor-in-chief Franz Rowe (2012) for an increase in the diversity of research genres. Rowe hopes the explicit encouragement of the call will work against what he describes as the pressure of researchers to produce 'incremental papers, with a quantitative standard methodology and a theory testing inclination'. These calls and acts by individual, influential editors are encouraging. Three specific proposals could be included:

- establishment, or in the case of MISQ the continuation, of a more diverse and larger review panel of academics;

- an increase in special issues that may cover research in different research domains and paradigms, and;

- the introduction of special issues or sections on regional areas such as special focus on information systems research in various countries for journals that wish to reflect an international perspective.

More radically, the journals must consider their role in the dissemination of research and the identification and support of quality in the digital age. Journals and academic presses act as the "de facto arbiters of hiring, tenure, and promotion' (Dawson, 2010:2). As such there is a danger that conformity will triumph over diversity. However, there is an opportunity to increase diversity as well. Open source reduces the distribution costs of journals to allow more issues and larger, more diverse review panels can review and constructively criticise and support a larger number of quality papers. That may be the next step for journals.

\section{REFERENCES}

"MIS Journal Rankings," in Association of Information Systems.

Adler, N., and Harzing, A. 2009. "When Knowledge Wins: Transcending the Sense and Nonsense of Academic Rankings," Academy of Management Learning and Education (8:1), pp 72-95.

Alavi, M., and Carlson, P. 1992. " A review of MIS research and disciplinary development," Journal of Management Information Systems (8:4), pp 45-62.

Avison, D., Dwivedi, Y. K., Fitzgerald, G., and Powell, P. 2008. "The beginnings of a new Era: Time to reflect on 17 years of the ISJ," Information Systems Journal (18:1), pp 5-21.

Ayanso, A., Lertwachara, K., and Vachon, F. 2007. "Diversity or Identity Crisis? An Examination of Leading IS Journals," Communications of the Association for Information Systems (20), pp 660- 680.

Barki, H., Rivard, S., and Talbot, J. 1993. "A Keyword Classification Scheme for IS Research Literature: An Update," MIS Quarterly (17:2), pp 209-226.

Benbasat, I., and Weber, R. 1996. "Research Commentary: Rethinking "Diversity" in Information Systems Research," Information Systems Research (7:4) December 1, 1996, pp 389-399. 
Benbasat, I., and Zmud, R. W. 2003. "The Identity Crisis within the IS Discipline: Defining and Communicating the Discipline's Core Properties," MISQ (27:2), pp 183-194.

Brockman, J. (ed.) Is the Internet Changing the Way You Think?: The Net's Impact on Our Minds and Future. Atlantic Books, London, 2011.

Busch, E., Nash, J., \& Bell, B. S. 2011. "Remote work: An examination of current trends and emerging issues.," Center for Advanced Human Resource Studies, Cornell University, Ithaca, NY.

Chen, W., and Hirschheim, R. 2004. "A paradigmatic and methodological examination of information systems research from 1991 to 2001," Information Systems Journal (14), pp pp 197-235.

Chua, W. F. 1986. "Radical Developments in Accounting Thought," The Accounting Review (61:4), pp 601-632.

Claver, E., Gonzalez, R., and Llopis, J. 2000. "An analysis of research in information systems (1981 1997)," Information \& Management (37), pp pp 181-195.

Comscore 2011. "Mobile Social Networking Audience Grew 44 Percent Over Past Year in EU5."

Dwivedi, Y., and Kuljis, J. 2008. "Profile of IS research published in the European Journal of Information Systems," European Journal of Information Systems (17:6), pp 678-693.

Farhoomand, A. F. 1987. "Scientific Progress of Management Information Systems," DATA BASE (18:4), pp 48-56.

Farhoomand, A. F., and Drury, D. H. 1999. "A historiographical examination of information systems," Communications of the Association for Information Systems (1), pp 1-27.

Galliers, R. D., and Meadows, M. 2003. "A Discipline Divided: Globalization and Parochialism in Information Systems Research," Communications of the Association for Information Systems (11:5).

Galliers, R. D., and Whitley, E. A. 2007. "Vive les differences? Developing a profile of European information systems research as a basis for international comparisons " European Journal of Information Systems ( 16, 20 - 35 1), pp 20-35.

Gallivan, M. J., and Benbunan-Fich, R. 2007. "Analyzing IS research productivity: an inclusive approach to global IS scholarship," European Journal of Information Systems (16:1), pp 36-53.

Gregor, S., Bunker, D., Cecez-Kecmanovic, D., Metcalfe, M., and Underwood, J. 2007. "Australian Eclecticism and Theorizing in Information Systems Research," Scandinavian Journal of Information Systems (19:1), pp 11-38.

Hillis, W. D. 2011. "Introduction: the Dawn of Entanglement," in Is the Internet Changing the Way You Think?: The Net's Impact on Our Minds and Future, J. Brockman (ed.), Atlantic Books: London.

Hutton, G., and Fosdick, M. 2011. "The globalization of social media," Journal of Advertising Research (51:4), pp 564-570.

InternetWorldStats 2011. "World Internet Usage and Population Statistics," in Internet World Stats, Miniwatts Marketing Group.

ITUTelecom 2011. "ICT Facts and Figures," ITU Telecom. 
Jacques, T. S., and Sebire, N. J. 2010. "The impact of article titles on citation hits: an analysis of general and specialist medical journals," Journal of the Royal Society of Medicine (1:2).

Kuhn, T. S. 1970. The structure of scientific revolutions, (2nd ed.) University of Chicago Press: Chicago, Ill.

Lamp, J. W. 2007. "Perceptions of Gender Balance of IS Journal Editorial Positions," Communications of the AIS (20), pp 124-133.

Lamp, J. W. 2011. Information categorisation: an emergent approach, $\mathrm{PhD}$, University of Melbourne.

Larsen, K. R., Monarchi, D. E., Hovorka, D. S., and Bailey, C. N. 2008. "Analyzing unstructured text data: Using latent categorization to identify intellectual communities in information systems," Decision Support Systems (45:4), pp 884-896.

Latour, B., and Woolgar, S. 1986. Laboratory life : the construction of scientific facts, (Princeton University Press: Princeton, N.J.

Lending, D., and Wetherbe, J. C. 1992. "Update on MIS Research: A Profile of Leading Journals and U.S. Universities," DATA BASE (23:2), pp 5-11.

Lincoln, Y. S. 2012. "The Political Economy of Publication: Marketing, Commodification, and Qualitative Scholarly Work," Qualitative Health Research) August 30, 2012.

Marx, K., and Engels, F. 1974. The German ideology. Part one, with selections from parts two and three ; together with Marx's Introduction to a critique of political economy and Theses on Feuerbach, (2nd ed.) Lawrence \& Wishart: London.

Mingers, J. 2003. "The paucity of multi-method research: a review of the information systems literature," Information Systems Journal (13), pp 233-249.

Mulki, J., Bardhi, F., Lassk, F., and Nanavaty-Dahl, J. 2009. "Set up remote workers to thrive," MIT Sloan Management Review (51:1), pp 63-69.

Nielson 2011. "The Social Media Report," in State of the Media, Nielsen.

Orlikowski, W. J., and Baroudi, J. J. 1991. "Studying information technology in organizations: research approaches and assumptions.," Information Systems Research (2:1), pp 1-28.

Özbilgin, M. F. 2009. "From journal rankings to making sense of the world.," Academy of Management Learning \& Education. (8:1), pp 113-121.

Palvia, P., Mao, E., Salam, A. F., and Soliman, K. S. 2003. "Management Information Systems Research: What's There in a Methodology?," Communications of the Association for Information Systems (11), pp 289-309.

Palvia, P., Pinjani, P., and Sibley, E. H. 2007. "A profile of information systems research published in Information \& Management," Information \& Management (44:1), pp 1-11.

Porter, M. E. 2001. "Strategy and the Internet," Harvard Business Review:March), pp 63-78.

Powell, P., and Woerndl, M. 2008. "Time to stop researching the important things? ," European Journal of Information Systems (17), pp 174-178.

Sansone, C., Morf, C. C., and Panter, A. T. 2004. "The Research Process: Of Big Pictures, Little Details, and the Social Psychological Road in Between," in The SAGE Handbook of Methods in Social Psychology, C. Sansone, C. C. Morf and A. T. Panter (eds.), SAGE. 
Sidorova, A., Evangelopoulos, N., Valacich, J. S., and Ramakrishnan, T. 2008. "Uncovering the Intellectual Core of the Information Systems Discipline," MIS Quarterly (32:3), pp pp.467482.

Simmons, B. A. "International Studies in the Global Information Age," International Studies Quarterly (55:3), pp 589-599.

Simmons, B. A. 2011. "International Studies in the Global Information Age," International Studies Quarterly (55:3), pp 589-599.

Smith, A. 2010. "Home Broadband 2010," Pew Research Center's Internet \& American Life Project.

van Dalen, H. P., and Henkens, K. 2012. "Intended and Unintended Consequences of a Publish-orPerish Culture: A Worldwide Survey " Journal of the American Society for Information Science and Technology (63:7), pp 1282-1293.

Vodanovich, S., Sundaram, D., and Myers, M. 2010. "Digital Natives and Ubiquitous Information Systems," Information Systems Journal (21:4), pp 711-723.

Vogel, D. R., and Wetherbe, J. C. 1984. "MIS research: a profile of leading journals and universities," DATA BASE (16:1), pp 3-14.

Weber, R. 2004. "The rhetoric of positivism versus interpretivism: a personal view (Editor's Comments)." MIS Quarterly (28:1), pp iii-xii.

Wenger, E. 1999. Communities of practice : learning, meaning, and identity, (Cambridge University Press: Cambridge.

Wilcocks, L., Whitley, E. A., and Avgerou, C. 2008. "The ranking of top IS journals: a perspective from the London School of Economics," European Journal of Information Systems (17), pp 163-168.

Yoo, Y. 2010. "Computing in everyday life: a call for research on experiential computing " MIS Quarterly (34:2), pp 213-231. 


\section{APPENDIX A}

\begin{tabular}{|c|c|c|c|c|c|c|c|c|c|c|c|c|c|c|c|c|c|c|}
\hline & 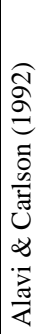 & 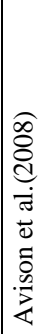 & 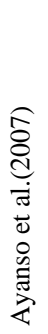 & 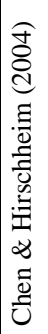 & 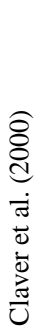 & 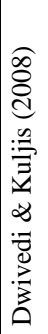 & 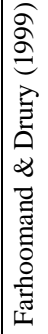 & 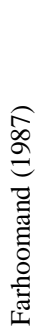 & 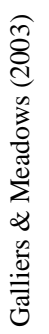 & 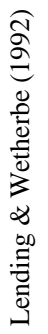 & 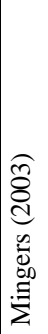 & 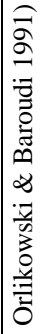 & 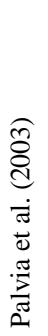 & 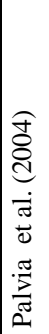 & 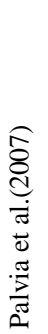 & 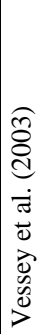 & 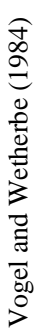 & 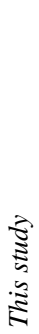 \\
\hline \multicolumn{19}{|l|}{ What } \\
\hline Treatment of IT artefact & & & $x$ & & & & & & & & & & & & & & & \\
\hline Topic / themes & $x$ & $x$ & $x$ & & $x$ & $x$ & $x$ & $x$ & & & & $x$ & $x$ & $x$ & $x$ & $x$ & & \\
\hline Theories used & & $x$ & & & & & & & & & & & & & & & & \\
\hline Reference discipline & & & & & & & $x$ & & & & & & & & & $x$ & & \\
\hline Research domain & & & & & & & & & & & & & & & & & & $x$ \\
\hline \multicolumn{19}{|l|}{ How } \\
\hline Empirical vs non-empirical & $x$ & $\mathrm{x}$ & & $x$ & $x$ & $x$ & $\mathrm{x}$ & & & $x$ & $\mathrm{x}$ & & & & & & & $x$ \\
\hline Quantitative/qualitative & & $x$ & & $x$ & & $x$ & & & & & & & & & & & & $x$ \\
\hline Research methods & $x$ & $x$ & $x$ & $x$ & $x$ & $x$ & $x$ & $x$ & & $x$ & $\mathrm{x}$ & $x$ & $x$ & $x$ & $x$ & $\mathrm{x}$ & $x$ & $x$ \\
\hline Research paradigm & & $x$ & & $x$ & & $x$ & & & & & $x$ & $x$ & & & & $x$ & & $x$ \\
\hline Unit/level of analysis & & & & & & $\mathrm{x}$ & & & & & & & & & & $x$ & & \\
\hline Longitudinal vs snapshot & & & & $x$ & & & & & & & & $x$ & & & & & & \\
\hline \multicolumn{19}{|l|}{ Who: authors } \\
\hline Individual researchers & & & & & & $x$ & & & & & & & & & $x$ & & & \\
\hline Academic/practitioner & $x$ & $\mathrm{x}$ & & & & $x$ & & & & & & & & & & & & $x$ \\
\hline Gender & & $x$ & & & & & & & & & & & & & & & & $x$ \\
\hline Home department & & $x$ & & & & & & & & & & & & & & & & $x$ \\
\hline University/ institute & & & & & & & & & & $x$ & & & & & $x$ & & $x$ & $x$ \\
\hline Region & & $\mathrm{x}$ & & & & $x$ & & & $x$ & & & & & & & & & $x$ \\
\hline Number authors & & & & & $x$ & & & & & & & & & & & & & $x$ \\
\hline \multicolumn{19}{|l|}{ :editors } \\
\hline Region & & & & & & & & & $x$ & & & & & & & & & $x$ \\
\hline Gender & & & & & & & & & & & & & & & & & & $x$ \\
\hline \multicolumn{19}{|l|}{ Where (research conducted): } \\
\hline Study setting & & & & & & & & & & & & & & & & & & $x$ \\
\hline Study region & & & & & & & & & & & & & & & & & & $x$ \\
\hline
\end{tabular}

Dimensions of diversity coded for in previous content analyses (this study final column) 


\section{Rationale for studies included in our analysis.}

Content analyses that were included: (i) had a clear focus on the IS discipline; (ii) employed a content analysis method (ie. papers were classified using a predefined classification scheme); (iii) investigated primarily journal articles (iv) investigated the adoption of at least one dimension of diversity, for instance, research methods or topics/themes. However excluded studies that focused on only a single aspect within that dimension such as only case studies within research methods; and (v) investigated articles published no earlier than the 1980s since arguably the discipline was changed considerably since that time. We also excluded research aimed at primarily analysing citation indexes and individual researcher productivity. 